\title{
Ocean thermal energy conversion
}

\author{
Aashay Tinaikar, Ajinkya Padate, Jainish Jain \\ Mechanical Engineering, Vidyavardhini’s College of Engineering And Technology, Mumbai, India
}

Email address:

harsh40m@gmail.com(A. Tinaikar), ajinkyapadate@gmail.com(A. Padate), jainishjain2719@gmail.com(J. Jain)

\section{To cite this article:}

Aashay Tinaikar, Ajinkya Padate, Jainish Jain. Ocean Thermal Energy Conversion. International Journal of Energy and Power

Engineering. Vol. 2, No. 4, 2013, pp. 143-146. doi: 10.11648/j.ijepe.20130204.11

\begin{abstract}
A closed cycle ocean thermal energy conversion basically involves a working fluid which has a boiling point just low below ambient temperature. This fluid is then evaporated using warm sea water and then used to run turbines. This evaporated gas is then condensed using cold seawater. In this paper a study is being made to install a super heater between the evaporator and the turbine. The various consequences due to this technical advancement have been discussed taking into consideration all the components in the OTEC plant. As the energy requirement to run pumps cannot be avoided, to increase the overall efficiency of the plant an effort is being made to increase the net energy output of the turbine. This can be achieved by heating the working fluid above its saturation temperature thus increasing its enthalpy indirectly increasing the net output of the turbine. Along with a super heater a pre-heater has been installed which helps to compensate the heat losses in heat exchangers. Both the super heater and pre-heater have been developed using non-conventional energy resources and no external energy input is required. Along with this an economic study has also been made which supports the proposed idea.
\end{abstract}

Keywords: Gradient, Desalinized, Super heater, Pre heater

\section{Introduction}

OTEC, Ocean Thermal Energy Conversion is an energy technology that converts solar radiation to electric power. OTEC systems use the ocean's natural thermal gradient, consequently the temperature difference between the warm surface water and the cold deep water below 800 meters by about $20 \mathrm{C}$, an OTEC system can produce a significant amount of power. The oceans are thus a vast renewable resource, with the potential to help us produce billions of watts of electric power. The cold seawater used in the OTEC process is also rich in nutrients and it can be used to culture both marine organisms and plant life near the shore or on land.

The total influx of solar energy into the earth is of thousands of times as great as Mankind's total energy use. All of our coal, oil and natural gas are the result of the capture of solar energy by life of the past. There have been many projects for harnessing solar energy, but most have not been successful because they attempt to capture the energy directly. The problem with this is that huge collectors must be deployed to do this, and resulting in large costs. The idea behind OTEC is the use of all natural collectors, the sea, instead of artificial collector.

\subsection{How Does It Work in Real Life}

Warm water is collected on the surface of the tropical ocean and pumped by a warm water pump. The water is pumped through the boiler, where some of the water is used to heat the working fluid, usually propane or some similar material. If it is cooler you can use a material with a lower boiling point like ammonia. The propane vapour expands trough a turbine which is coupled to a generator that generating electric power. Cold water from the bottom is pumped through the condensers, where the vapour returns to the liquid state. The fluid is pumped back into the boiler. Some small fraction of the power from the turbine is used to pump the water through the system and to power other internal operations, but most of it is available as net power.

\subsection{Closed Cycle, Open Cycle, Hybrid Cycle}

There are three types of OTEC designs: open cycle, closed cycle, and hybrid cycle. In an open cycle, seawater is the working fluid. Warm seawater is pumped into a flash evaporator where pressure as low as 0.03 bar cause the water to boil at temperatures of $22^{\circ} \mathrm{C}$. This steam expands through a low-pressure turbine connected to a generator to create power. The steam then passes through a condenser using cold seawater from the depths of the ocean to condense the steam into desalinized water. 


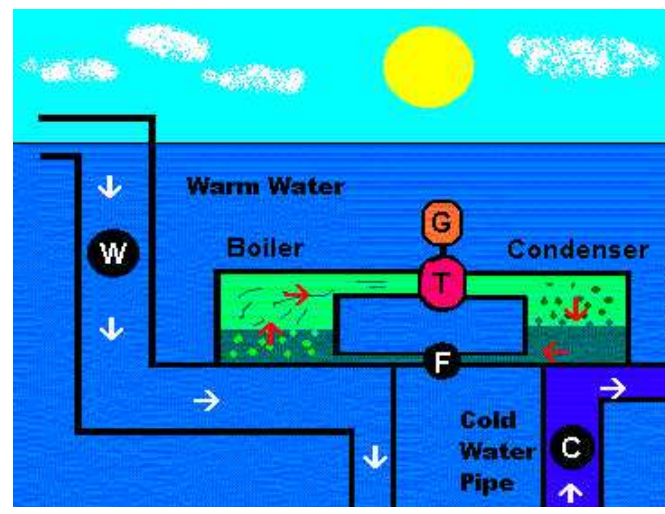

Figure1. Schematic diagram of OTEC cycle

In a closed cycle, a low boiling point liquid such as ammonia or another type of refrigerant is used as the working fluid in a Rankine cycle (common steam cycle). The heat from warm seawater flowing through an evaporator vaporizes the working fluid. The vapor expands through a turbine, then flows into a condenser where cold seawater condenses it into a liquid.

A hybrid cycle is a combination of both closed and open cycles where flash evaporator seawater is used as the closed cycle working fluid. This is a cycle wherein, electricity is produced in first stage followed by water production in second stage.

\section{Aims and Objectives}

To increase the net energy output of an OTEC closed cycle by incorporating a superheater which acts as an additional source of heat. Superheater acts as a heat exchanger which transfers direct heat from sun to the working fluid.

\section{Methodology}

\subsection{Structural Advances}

\subsubsection{Super-Heater}

In the proposed design, a black metallic plate of aluminum is installed on the OTEC plant, above the water surface. This plate absorbs maximum solar radiation and gets heated up upto a temperature of $43^{\circ} \mathrm{C}$. This heat is transferred to the evaporated working fluid by means of connecting rods.

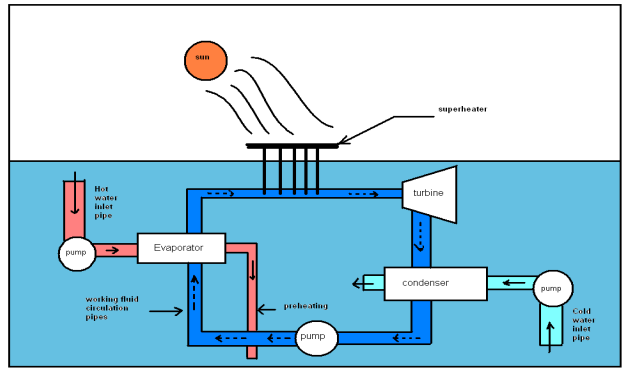

Figure2. Modified OTEC cycle schematic diagram

\subsubsection{Pre heater}

The outlet sea water from the evaporator is $12^{\circ} \mathrm{C}$ warmer than the working fluid coming out of the condenser. This fact is used to preheat the working fluid before it advances into the evaporator. This further compensates the heat loss from the heat exchangers; also it increases the working time of the OTEC plant.

This preheating increases the efficiency from 3.07 to $3.11 \%$ - a useful increase. Thus preheating provides gain both in heat absorbed and conversion efficiency.

\subsubsection{Working Fluid}

The working fluid used is propane or ammonia. Propane has Boiling point approximately $23.9^{\circ} \mathrm{C}$ and freezing point of $14^{\circ} \mathrm{C}$, with a dew point of $7^{\circ} \mathrm{C}$. In a closed cycle, the working fluid is pumped into a heat exchanger where it exchanges heat with surface water, which is at $29^{\circ} \mathrm{C}$ in tropical areas. After passing through the heat exchanger, the working fluid vaporises with a dryness fraction of $97 \%$.

Superheating is a process of directly heating the saturated vapour from highest temperature source available. This additional heating occurs at constant pressure and increases the enthalpy, thus remaining vapour droplets also gets converted to vapour. Evaporator temperature is $4^{\circ} \mathrm{C}$ less than the incoming sea water, so to improve this state of working fluid we can superheat it by $3-4^{\circ} \mathrm{C}$ in order to reduce erosion problems in turbine.

The working fluid temperature would be increased by $4^{\circ} \mathrm{C}$ by absorption of $134 \mathrm{KW}$ of heat. This increases the dryness fraction from $97 \%$ to $98 \%$.

\subsubsection{Net Energy Output}

The net energy output depends upon the velocity with which the turbine blades rotate. This depends upon the kinetic energy of the working fluid entering the turbine. This kinetic energy of the working fluid is governed by the enthalpy of the gas. Superheating increases the temperature of the working fluid which increases its enthalpy. Thus superheating the gas indirectly increases the net energy output of the turbine. As all the other energy requirements in pumps is unavoidable, the only source of increasing the net output of the OTEC plant is to increase the gross output of the turbine.

Statistical data for 1MW OTEC plant

Gross output of turbine $=1 \mathrm{MW}$

Net energy output $=493 \mathrm{KW}$

Pump capacity (cold water $)=292 \mathrm{KW}$

Pump capacity (hot water) $=197 \mathrm{KW}$

Working fluid pump capacity $=18 \mathrm{KW}$

Net energy output in new design

Net energy output $=593 \mathrm{KW}$

Thus $100 \mathrm{KW}$ of additional energy is added to the net energy output of the OTEC plant due to installation of super heaters and pre-heaters

\subsubsection{Material Selection for Heat Exchangers}

Two heat exchanger systems, evaporators and condensers, comprise a large part of the total capital cost for an OTEC 
power plant. The current system design calls for titanium plate-and-frame heat exchangers, which comprise about one-quarter of the $\$ 150$ million capital cost for a proposed 10 MW closed-cycle plant-ship. Maintenance and replacement costs for this heat exchanger subsystem can be estimated at roughly $10 \%$ of the exchanger cost and will occur twice during the exchanger's 30-year expected lifetime. According to OCEES International, demand for titanium has increased greatly in recent years, which is reflected in higher material costs and decreased availability for heat exchangers. For these two reasons, it is desirable to find an alternative to titanium exchangers. Aluminium, steels, and polymers have all been evaluated to some extent as candidate materials in previous research. However, material advancements applicable to new OTEC heat exchangers have been made primarily in the field of thermally conductive polymers. Thus, polymer exchangers were chosen because they represent an under-developed and novel portion of the heat exchanger market.

\section{Location of OTEC Plant}

Except for closed basins, such as the Mediterranean and Red Seas, deep seawater flows from the polar regions: polar water, which represents up to $60 \%$ of all seawater, originates mainly from the Arctic for the Atlantic and North Pacific Oceans, and from the Antarctic (Weddell Sea) for all other major oceans. Therefore, Tc at a given depth, approximately below $500 \mathrm{~m}$, does not vary much throughout all regions of interest for OTEC. It is also a weak function of depth, with a typical gradient of $1{ }^{\circ} \mathrm{C}$ per $150 \mathrm{~m}$ between $500 \mathrm{~m}$ and 1000 $\mathrm{m}$. These considerations may lead to regard Tc as nearly constant, with a value of $4^{\circ} \mathrm{C}$ at $1000 \mathrm{~m}$.

Two facts require caution, however, during the OTEC site selection process:1) OTEC is very sensitive to any loss of thermal resource, and 2) the Cold Water Pipe is a costly plant component. Consequently, variations in Tc that appear to be small may have a drastic impact on the performance and/or the capital cost of the OTEC plant. For Example, Pacific Ocean deep $(1000 \mathrm{~m})$ water at low latitudes is

Longitude

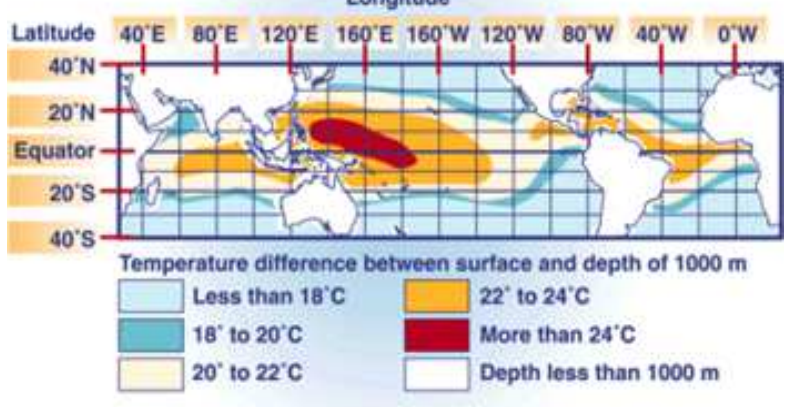

Figure3. OTEC favorable zones colder by about $1^{\circ} \mathrm{C}$ than Atlantic Ocean deep water; in the case of the East Coast of Africa, various phenomena including mixing with Red Sea outflow elevate the Indian Ocean water temperature (at $1000 \mathrm{~m}$ depth) to more than $6^{\circ} \mathrm{C}$. As for the optimal depth at a given land-based OTEC site, seafloor bathymetry and topography play an important role and some degree of thermo-economic optimization is required.

\section{Co-Products of OTEC}

The seawater needed for OTEC can also be used to support mariculture operations. The cold seawater contains large quantities of the nutrients required to sustain marine life. Organisms already grown in this environment include algae, seaweeds, shell fish and fin fish. The cold seawater can also be used as the chillier fluid for air-conditioning systems.

In considering the economics of OTEC, it is appropriate to determine if multiple-product systems (e.g.: electricity, desalinated water, mariculture, AC systems) yield higher value by, for example, decreasing the equivalent cost of electricity. Unfortunately mariculture operations, as in the case of AC systems, can only use a relatively minute amount of the seawater required for OTEC systems. For example, the cold water available from a 1 MW OTEC plant could be used for daily exchanges of twenty-five $100 \mathrm{~m} \times 100 \mathrm{~m} \times 1 \mathrm{~m}$ mariculture ponds, requiring at least 25 ha. Moreover, no mariculture operation requiring the use of the high-nutrient-deep-ocean water has been found to be cost effective. It is, therefore, recommended that OTEC be considered for its potential impact in the production of electricity and desalinated water and that mariculture and AC systems, based in the use of deep ocean water, be considered decoupled from OTEC.

\section{Benefits and Drawbacks}

\subsection{Benefits}

1. The net energy output of the plant increases by approx. $20.3 \%$ which is considerably high.

2. Suitably designed OTEC plants will produce little or no carbon dioxide or other polluting chemicals.

3. The installation of a pre-heater increases the working time constraint of the OTEC plant in a particular day.

4. The use of OTEC as a source of electricity will help reduce the state's almost complete dependence on imported fossil fuels.

\subsection{Drawbacks}

1. OTEC-produced electricity at present would cost more than electricity generated from fossil fuels at their current costs.

2. OTEC plants must be located where a difference of about $20^{\circ} \mathrm{C}$ occurs year round. Ocean depths must be available fairly close to shore-based facilities for economic 
operation. Floating plant ships could provide more flexibility.

3. No energy company will put money in this project because it only had been tested in a very small scale.

4. The cost of the OTEC plant increases by $21 \%$ by installation of a super heater and a pre-heater.

\section{Conclusion}

Installation of super heater and pre-heater increases the net energy output of OTEC plant. To decrease the cost of heat exchangers search for more durable Polymer heat exchangers, which are more efficient at lower cost is carried out. Also the design of metallic plate is being improved, to transfer maximum energy to the working fluid.
Thus a study to improve the efficiency of OTEC plant has been successfully carried out.

\section{References}

[1] Luis A. Vega, Economics of Ocean Thermal Energy, American Society of Civil Engineers, 1992

[2] Dr. Hans Krock, Preliminary Analysis of Polymer Heat Exchangers

[3] Maria Bechtel and Erik Netz, OTEC

[4] H.P.Gupta, Solar Engineering

[5] Ruperi Mario, OTEC in Pacific Island 